\title{
RESENHA DO LIVRO “CAPOEIRA UMA HERANÇA CULTURAL AFRO-BRASILEIRA", ESCRITO POR ELISABETH VIDOR E LETÍCIA REIS, EDITORA SELO NEGRO, 2013
}

\author{
BOOK REVIEW: "CAPOEIRA - UMA HERANÇA CULTURAL AFRO-BRASILEIRA", \\ BY ELISABETH VIDOR AND LETÍCIA REIS. SELO NEGRO, 2013
}

REVISIÓN DEL LIBRO "CAPOEIRA UMA HERANÇA CULTURAL AFROBRASILEIRA", ESCRITO POR ELISABETH VIDOR Y LETÍCIA REIS, EDITORIAL SELO NEGRO, 2013

Jorge Felipe Columá ${ }^{\star}$ Simone Freitas Chaves ${ }^{\star}$, Felipe da Silva Triani ${ }^{\star *}$

Palavras chave:

Capoeira.

Esportes.
História do Brasil.

Resumo: A resenha discute a capoeira brasileira, com ênfase no cenário carioca. A obra traça os aspectos históricos do esporte, destacando a capoeiragem carioca e as maltas de capoeira que incomodaram as elites do Rio de Janeiro. A origem da capoeira descrita na obra é alvo de crítica pelos resenhistas, uma vez que nas referências obtidas por eles há três hipóteses para o surgimento da capoeira e que as referências sobre a origem nos quilombos não apresentam argumentos plausíveis. Vidor e Reis narram a história de dois ícones, sendo eles mestre Bimba, que influenciou na institucionalização da capoeira como esporte e luta, sendo seu legado a capoeira Regional, e mestre Pastinha, que contribuiu na difusão da cultura brasileira internacionalmente, sendo representante da capoeira Angola. A resenha apresenta ainda a interpretação cultural da capoeira realizada pelas autoras através do universo simbólico representado no esporte que vai da roda ao berimbau.

\section{Keywords:}

Capoeira.

Brazilian History.

Sports.

Palabras clave: Capoeira.

Historia de Brasil. Deportes.

\begin{abstract}
The review discusses Brazilian capoeira, focusing on Rio de Janeiro. The work covers the sport's historical aspects, highlighting Rio de Janeiro capoeira and capoeira groups that troubled local elites. The origin of the capoeira described in this work is criticized by the reviewers, since their references include three hypotheses for the emergence of capoeira, and those about the origin of quilombos have no plausible arguments. Vidor and Reis narrate the story of two icons, namely, Master Bimba, who influenced the institutionalization of capoeira as sport and fight, and his legacy was Regional Capoeira; and Master Pastinha, who helped spreading Brazilian culture internationally as a representative of Angola capoeira. The review also presents the authors' cultural interpretation of capoeira through the symbolic universe represented in the sport, from the Capoeira round to the berimbau.
\end{abstract}

Resumen: La revisión discute la capoeira brasileña, con énfasis en Rio de Janeiro. La obra traza los aspectos históricos de ese deporte, destacando la capoeira carioca y las pandillas de capoeira que molestaron a la élite de Rio de Janeiro. El origen de la capoeira que se describe en la obra es objeto de las críticas de las autoras, ya que en las referencias obtenidas por ellas hay tres hipótesis para el surgimiento de la capoeira y las referencias sobre el origen de los quilombos no presentan argumentos plausibles. Vidor y Reis narran la historia de dos íconos, maestro Bimba, que influenció la institucionalización de la capoeira como deporte y lucha, y maestro Pastinha, quien contribuyó en difundir la cultura brasileña a nivel internacional. La revisión también presenta la interpretación cultural de la capoeira realizada por las autoras a través del universo simbólico representado en el deporte, que va de la rueda al berimbau.
*Universidade do Estado do Rio de Janeiro (UERJ). Rio de Janeiro, RJ, Brasil.

E-mail: jorgecoluma@ig.com.br

**Universidade do Grande Rio (UNIGRANRIO). Rio de Janeiro, RJ, Brasil.

E-mail: felipetriani@gmail.com

Recebido em: 12-11-2014

Aprovado em: 26-03-2015

(c) (1) (8) Licence 
O livro começa com um deleitoso prefácio escrito por Antonio Filogenio de Paula Junior, abordando a influência da capoeira como elemento da cultura nacional e destacando a importância desse estudo. Além de atender os pressupostos legais que preconizam conteúdos de matrizes africanas nas escolas, discute a habilidade do negro em dialogar com a difícil realidade da escravidão no Brasil. Filogenio ratifica a importância de grandes mestres de capoeira e nos convida a conhecer alguns símbolos discutidos pelas autoras ao longo da obra.

O livro é dividido em três capítulos: o primeiro apresenta aspectos históricos, destacando a capoeiragem carioca e as maltas de capoeira que tanto incomodaram os governantes e as elites no Rio de Janeiro. Já no segundo é apresentado um pequeno perfil dos Mestres Bimba e Pastinha, dois ícones para a capoeira que detêm fama até os dias atuais. Por fim, no terceiro capítulo desvelam-se alguns traços simbólicos da modalidade (VIDOR; REIS, 2013) que arrebata praticantes em aproximadamente 154 países (DA COSTA, 2005).

No primeiro capítulo as autoras adentram a história da capoeira com um dado polêmico, já que apontam uma probabilidade pueril de que a capoeira surgira nos quilombos, no período do Brasil Colônia (VIDOR; REIS, 2013). Ora, em que pese tal colocação, revisitemos a literatura existente sobre a capoeira e alcançaremos as três hipóteses mais recorrentes para o surgimento da modalidade no Brasil. São elas: a hipótese rural, que indica que a capoeira era praticada nos matos baixos, nomeados na língua tupi-guarani de caapuera, chamados de capoeira (MOREIRA, 2011). A hipótese, conhecida por urbana, que aponta o surgimento da capoeira nas praças do mercado de aves, na cidade do Rio de Janeiro, é respaldada nas obras de De Los Rios (2000), Brasil Gerson (1965) e consolidada por Soares (1994), que investiga os arquivos criminais da cidade do Rio de Janeiro e afirma serem urbanos os primeiros registros da chamada capoeiragem. Existe ainda outra hipótese que avalia ser africana a raiz da capoeira, que teria nascido de um ritual chamado N'golo, em que os jovens guerreiros de uma etnia africana (Mucopi), disputariam as jovens que obtinham sua primeira menarca em um ritual de passagem que, segundo os defensores dessa teoria, parece bastante com a capoeira (BOLA SETE, 1997). Vale ressaltar que essa probabilidade é bastante presente nos discursos da capoeira angola ${ }^{1}$ e seus adeptos, que parecem querer estabelecer um elo com uma suposta africanidade perdida (MOREIRA, 2011).

As referências sobre a capoeira nos quilombos podem ser questionadas, pois as autoras (VIDOR, REIS, 2013) que as sustentam não apresentam dados ou argumentos plausíveis que sustentem uma tese sobre uma capoeira quilombola. Da Costa (2005) e ODC² (1907), trazem esses dados, porém sem fazer referência a alguma fonte, ou algum outro apontamento substancial. Soares (1994) infere que essas primeiras informações inauguram uma versão romântica sobre o surgimento da capoeira, presente no imaginário de muitos mestres de capoeira até os dias atuais.

No decorrer do capítulo é descrita a história da capoeira e como foi perseguida e criminalizada no Rio de Janeiro. Nesta epopeia entra em cena o antigo capoeira, que, reunido em maltas, assombra as elites cariocas, seja em pequenos crimes, seja em associações com os políticos da época. Episódios como a Guerra do Paraguai, Revolta da Vacina e outros distúrbios urbanos revelam célebres personagens capoeiras, como Prata preta ${ }^{3}$ e Manduca da

\footnotetext{
1 Sistema de capoeira representado por Mestre Pastinha e outros mestres, que procura uma ligação direta com a ancestralidade africana, este sistema procura se diferenciar, sobretudo, da capoeira Regional criada por Mestre Bimba.

2 Trata-se de uma obra em que o autor se ocultou sob as iniciais ODC (Ofereço, Dedico e Consagro). 
Praia ${ }^{4}$, que entre tantos outros anônimos desfilaram sua ginga e sua navalha desde a Corte até o começo da República (MOREIRA, 2011).

No segundo capítulo é apresentado um pequeno perfil de dois grandes mestres de capoeira da Bahia, responsáveis por difundir a capoeira a partir da década de 1930 e que deram subsídios para a institucionalização da capoeira como conhecemos hoje. São eles mestre Bimba e Pastinha. Na descrição de mestre Bimba é atribuída sua importância na descriminalização da capoeira, sua divulgação como esporte e luta. Mestre Bimba é retratado também como um divisor de águas, um facilitador que contribuiria para um novo patamar da modalidade. Neste sentido Vidor e Reis (2013) reconhecem o legado de mestre Bimba para o atual panorama da capoeira em escolas, academias, clubes.

Aspectos internos da academia do mestre Bimba são citados, inclusive suas disputas, seus enfrentamentos contra outros capoeiristas e demais lutadores. As autoras descrevem o causo sobre a apresentação de capoeira que mestre Bimba realizou para Getúlio Vargas e detalhes sobre a criação de seu maior legado, a capoeira Regional. Com habilidade e sensibilidade as autoras discorrem sobre a melancolia de seus últimos dias, longe da Bahia e de seus alunos, com dificuldades, vindo a falecer em Goiás, triste e desamparado.

Mestre Pastinha também é retratado de forma competente pelas autoras, que lamentam a ausência de uma biografia do mestre que mais representa a capoeira Angola. Porém, duas obras foram importantes para nortear esse perfil, são elas: o disco Mestre Pastinha e sua academia (1969) e o livro de autoria do mestre, Capoeira Angola (1964). As autoras traçam uma linha do tempo desde seu início na capoeira, passando pelo militarismo, sua veia artística como pintor e artesão, e depois professor de capoeira na Bahia. Vale a observação que Mestre Pastinha fora também engraxate e leão de chácara, tendo inclusive vários episódios de enfrentamentos com a polícia.

Entretanto foi como capoeirista que o mestre se notabilizou, liderando o movimento de capoeira que não aderiu à novidade da capoeira Regional (ABREU, 2003). As autoras trazem as diferenças na gênese da capoeira Angola e Regional, sobretudo em sua formação. Enquanto a primeira iria se nutrir de movimentos do batuque ${ }^{5}$, da capoeira antiga e outras lutas, a segunda nasceria da mandinga dos escravos em situação desfavorável de escravidão.

É destacada a viagem de mestre Pastinha à África e sua importância para a difusão da cultura brasileira internacionalmente. Por fim, as autoras descrevem o triste fim do mestre que também enfrentou dificuldades em seus últimos dias, culminando com sua morte, já cego e bastante debilitado, em um abrigo público aos 92 anos.

Enquanto mestre Bimba fica reconhecido como o criador da capoeira Regional, Pastinha se insere na história como representante da capoeira Angola. Mestre Bimba e Pastinha tornam-se as principais figuras míticas, sendo referências aos praticantes da capoeira (PIRES, 2002).

No terceiro capítulo tenta-se desvelar o universo simbólico presente na capoeira, utilizando a metáfora do mundo de pernas para o ar. A partir de alguns movimentos de inversão utilizados na roda de capoeira, como a bananeira, queda de rins e outros em que literalmente

4 Afamado capoeira, frequentador das páginas policiais da época; pardo, alto, corpulento e arruaceiro, sempre trajando calça larga para facilitar os movimentos e sua elegante jaqueta branca (EDMUNDO, 1957). 
o jogador fica com as pernas para o ar. Neste sentido, a obra sugere um olhar para o mundo a partir dos códigos da capoeira, uma inversão de valores ocidentais em oposição a inclinações afro-brasileiras.

Inicia-se então discutindo a capoeira como uma luta perigosa, em que o capoeirista, além de vencer seu contendor fisicamente, lança mão de recursos psicológicos que subjugam emocionalmente seu adversário. Gritos, palavras chulas e piadas, além de desestabilizar seu oponente, o desmoralizam perante os assistentes. Astúcia, surpresa e picardia constituem 0 capoeirista, tornando-o um adversário a ser evitado, afinal: "[...] manha e malícia se sobrepõem a força física, pois o mais forte não é aquele fisicamente avantajado (por mais robusto e pesado que seja), mas o mais malicioso, o mais mandingueiro" (VIDOR; REIS, 2013, p. 70).

As autoras comparam esse modus operandi do capoeirista à resposta dada pelas classes populares ao poder hegemônico e agressivo dos dominantes, já que os enfrentam pelas "beiras" e não frente a frente, local em que o mais forte parece reinar. Sodré (2002) defende que os movimentos da capoeira refletem o modo como o negro teve que negociar com o trabalho compulsório e as condições precárias de vida durante o Brasil Colônia, sendo assim, a ginga, a negaça e o engano eram armas de sobrevivência nas grandes cidades, era a treta subvertendo a letra.

$\mathrm{Na}$ obra, a roda de capoeira é descrita como "[...] um círculo de 2,5 metros de raio, circundado por outro. Entre ambos há uma distância de 10 centímetros de largura" (VIDOR; REIS, 2013, p. 72). A roda descrita acima nos remete àquelas feitas em recintos fechados ou academias, pois nas rodas realizadas em locais informais, ou mesmo na rua, como reza a tradição, dificilmente há espaços para uma marcação milimétrica como fazem as autoras. Já, Silva (2003), descreve a roda de capoeira como um mundo simbólico, feito em:

Pequenos metros, por dois jogadores ao som de uma orquestra de tocadores de percussão, sob a animação de vários(as) capoeiristas em forma de círculo, uma espécie de disputa dançada, e no qual o espaço se parece ter intenção de conquista e superação (SILVA, 2003, p. 90).

Para este autor, dentro da roda se inserem símbolos e signos, construídos através de movimentos circulares. A linguagem corporal, neste sentido, é de extrema importância, já que ela pode desvelar alguns significados contidos na roda. Esses significados podem aparecer imbricados em alguns códigos dos capoeiristas, como o berimbau, a roda, etc.

No dicionário de símbolos de Chevalier e Gheerbrant (2003, p. 783) encontra-se uma concepção de roda diferente da concepção perfeita de círculo, mas com uma parcela de imperfeição, pois a roda "[...] se refere ao mundo do vir a ser, da criação contínua, portanto da contingência e do perecível. Simboliza os ciclos, reinícios e renovações", ou seja, os ritos e as manifestações culturais de um povo. Cascudo (2001) descreve as danças em roda como de origem milenar, estando presente em todas as culturas e no Brasil, praticadas entre portugueses, africanos e indígenas. Portanto pode-se entender a roda como espaço ritual de vivências, que atribuem profundo sentido aos capoeiristas, significando mais que dois corpos jogando capoeira, talvez uma metáfora da própria vida.

As orquestras de instrumentos da capoeira que compõem a roda, berimbaus, atabaque, pandeiro, agogô e reco-reco são apresentadas, com destaque ao berimbau, símbolo principal e responsável pela maestria da orquestra e, consequentemente, da roda. Quanto ao berimbau, 
podemos, também, atribuir a ele um papel de catalisador de energias, fazendo uma ponte imaginária entre o orun ${ }^{6}$ e 0 aiề (MOREIRA, 2011).

O berimbau pode determinar pelo ritmo entoado o tipo de jogo, se Angola ou Regional, se lento ou rápido, se "solto" ou "amarrado". As cantigas estão diretamente ligadas ao toque do berimbau, as autoras descrevem as variações de cantigas e suas funções na roda, desde as cantigas de desafio, até as cantigas históricas que perpassam por fatos da história dos povos afrodescendentes e, consequentemente, do Brasil.

As cantigas são apontadas como uma espécie de portal condutor para a roda e seus símbolos, sagrados e profanos, em que se "paga" para adentrar e se benze tocando o chão para pedir proteção na roda. Cabe ressaltar que, em rodas atuais, existem pessoas de diferentes religiões, logo, quando esta observação é feita, uma quantidade significativa de capoeiristas são excluídos, uma vez que não aderem a esses códigos, movidos por seus dogmas e ideologias.

Uma relação interessante desenvolve-se entre os movimentos de inversão, de pernas para o ar, e os movimentos realizados com os pés no chão, sem a inversão. Nesta relação, é atribuído maior valor aos movimentos do chamado baixo corporal, que, segundo as autoras, subvertem a ordem hegemônica, que atribui maior valor às mãos, à cabeça e ao tronco, situados no chamado alto corporal. Na esteira das autoras pode-se inferir que esses códigos pertencem em maior parte à capoeira Angola, que em sua performance estética nos remete às descrições supracitadas.

Quando Mestre Bimba, o criador da capoeira Regional, foi perguntado qual o seu golpe de preferência, o mestre respondeu: "galopante, porque mantenho meus pés no chão". O galopante é uma espécie de tapa aplicado com a mão em concha na direção dos tímpanos, bastante utilizado nos jogos de São Bento Grande da Regional, sobretudo quando os jogos ficam mais disputados, duros, se contrapondo à associação feita pelas autoras.

As autoras, porém, são felizes ao estabelecer outras relações simbólicas de confronto entre 0 alto e o baixo corporal, como na passagem em que indicam 0 ataque com membros inferiores direcionados à cabeça do adversário, órgão responsável pelo pensamento e consequentemente o comando do nosso corpo, uma bela metáfora de subversão simbólica da vida cotidiana em que os mais abastados subjugam os menos favorecidos, afinal, para as autoras, a cabeça vem a representar o topo da pirâmide, norteando os pés ou a base da pirâmide social, que na capoeira assume o papel de principal peça de contusão, enquanto a cabeça 0 alvo a ser encontrado.

A ginga da capoeira também é fruto de análise pelas autoras, que a colocam como movimento fundamental para o jogo. Concordamos quando indicam a ginga como movimento metafórico do diálogo do negro escravo com uma sociedade que o maltratava, neste sentido, as autoras enfatizam a ginga e seus artifícios do não enfrentamento, da ocupação dos interstícios. Podemos encontrar eco no conceito de sincopa, característica das manifestações afro-americanas, que ocupam essas mesmas gretas sociais e simbólicas vivenciadas pelos africanos e seus descendentes até os dias atuais (SODRÉ, 1998).

Nesse universo simbólico encontram-se elementos como a mandinga, presente na ginga e também no imaginário popular brasileiro. Esse termo apresenta uma polissemia que

6 Espaço mítico onde os deuses da cultura nagô habitam, em muito se assemelha ao céu paradisíaco de outros povos. (OGBEBARA, 1998). 7 Mundo dos mortais, como a terra para os ocidentais. (OGBEBARA, 1998). 
remete os capoeiristas a traços da religiosidade africana, como feitiçaria ou poderes mágicos, e também uma possível malandragem, uma dissimulação dentro do jogo de capoeira e na vida dos praticantes.

Ao finalizar, as autoras apresentam a capoeira Angola e a Regional como elementos de diálogo permanente com essa realidade histórica nascida no tráfico, no trabalho compulsório dos negros africanos e na realidade de uma vida longe de sua terra natal em condições totalmente adversas. São duas faces de uma mesma moeda moldada nos artifícios da ginga e seus elementos como a mandinga, a sincopa e o engano para ludibriar, subverter a ordem hegemônica e ocupar os espaços sociais negados na maioria das vezes.

\section{REFERÊNCIAS}

ABREU, Frede. O Barracão do mestre Waldemar. Salvador: Zarabatana, 2003.

BOLA SETE, Mestre. A capoeira angola na Bahia. 2. ed. Rio de Janeiro: Pallas, 1997.

CASCUDO, Luis da Câmara. Dicionário do folclore brasileiro. 11. ed. São Paulo: Global, 2001.

CHEVALIER, Jean; GHEERBRANT, Alain. Dicionário de símbolos: mitos, sonhos, costumes, gestos, formas, figuras, cores, números. 18. ed. Rio de Janeiro: José Olympio, 2003.

DA COSTA, Lamartine Pereira. Atlas do Esporte no Brasil. Rio de Janeiro: Shape, 2005.

DE LOS RIOS, Adolfo Morales. O Rio de Janeiro Imperial. Rio de Janeiro: Topbooks, 2000.

GERSON, Brasil. História das ruas do Rio. 4. ed. Rio de Janeiro: Brasiliana, 1965.

MOREIRA, Jorge Felipe Fonseca. Da navalha ao berimbau: a malandragem no imaginário da capoeira carioca. 2011. 191 f. Tese (Doutorado em Educação Física) - Programa de PósGraduação em Educação Física, Universidade Gama Filho, Rio de Janeiro, 2011.

ODC. Guia do capoeira ou Gymnástica Brazileira. 2. ed. Rio de Janeiro: Livraria Nacional, 1907.

OGBEBARA, Awofa. IGBADU: A Cabaça da Existência: mitos nagô revelados. Rio de Janeiro: Pallas, 1998.

PIRES, António Liberac Cardoso Simões. Bimba, Pastinha e Besouro de Mangangá: três personagens da capoeira baiana. Tocantins/ Goiânia: NEAB/ Grafset, 2002.

SILVA, José Milton Ferreira da. A linguagem do corpo na capoeira. Rio de Janeiro: Sprint, 2003.

SOARES, Carlos Eugênio Líbano. A negregada instituição: os capoeiras no Rio de Janeiro. Rio de Janeiro: Secretaria Municipal de Cultura, 1994.

SODRÉ, Muniz. Samba: o dono do corpo. Rio de Janeiro: Mauad, 1998.

SODRÉ, M. Mestre Bimba: corpo de mandinga. Rio de Janeiro: Manati, 2002.

VIDOR, Elisabeth; REIS, Letícia Vidor de Sousa. Capoeira: uma herança cultural afro-brasileira. 